\title{
IDENTIDADES CONJUNTURAIS x IDENTIDADE TRADICIONAL
} As múltiplas faces da teuto-brasilidade no interior de São Paulo

\author{
Olga Rodrigues de Moraes von Simson*
}

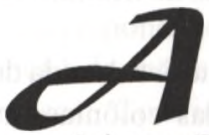

existência de uma importante influência econômica, social e cultural germânica no Estado de São Paulo é pouco percebida porque se faz entremeada ao tecido social local e resulta de um longo processo imigratório que, iniciado em 1829 com os 94 colonos que se fixaram na Colô- nia Velha de Parelheiros próxima a Santo Amaro, encontrou o seu auge na segunda metade do século passado, mas continuou ainda com picos elevados no período posterior às duas grandes guerras mundiais.

A significativa massa populacional de língua e cultura germânicas ocupou preferencialmente certos bairros da capital (San- to Amaro, Brooklyn, Tucuruvi, Tremembé, Vila Mariana), mas também deixou suas marcas em várias cidades do interior (Rio Claro, Campinas, Cosmópolis, Limeira), como se pode perceber pelo quadro elaborado em 1857 relacionando as colônias que receberam imigrantes de língua e cultura germânicas no interior de São Paulo.

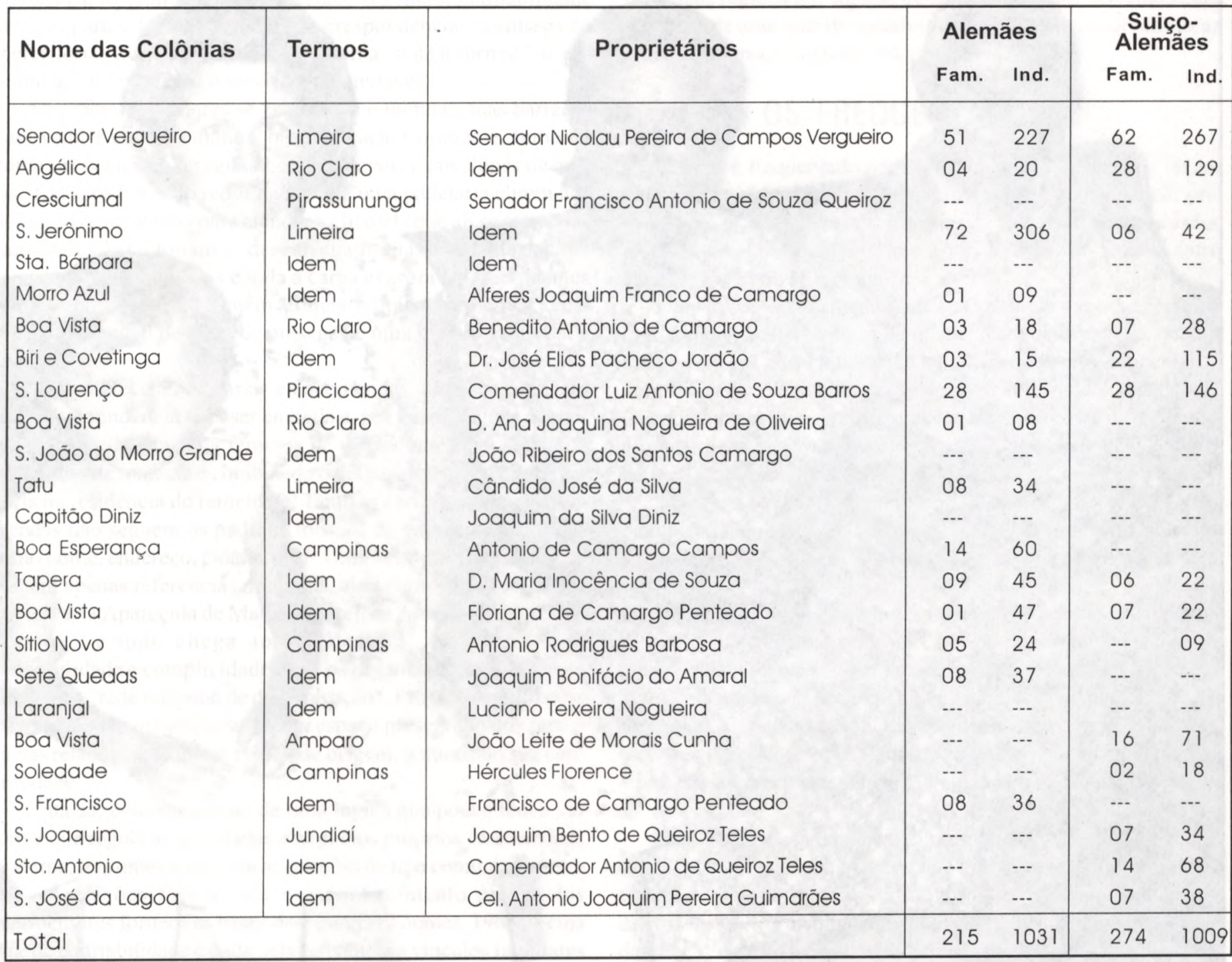

Fonte: Davatz, Thomas. Memórias de um colono no Brasil (1850). Tradução, prefácio, notas de Sérgio Buarque de Holanda - B. Horizonte, Ed. Itatiaia/S. Paulo, EDUSP, 1980, p.38. 
Poucas são, entretanto, as pesquisas realizadas tentando dar conta desse tema, sob um enfoque de caráter histórico-sociológico. Com esse objetivo iniciamos em 1992 uma pesquisa que, tentando resgatar o processo imigratório de alemães para Campinas e região, nos permitiu perceber a abrangência e importância do fenômeno no Estado de São Paulo'

Nosso objetivo ao estudar os descendentes de alemães no município de Campinas foi o de reconstruir a história social do processo de imigração, fixação e integração desse grupo na vida local e tentar compreender como, na atualidade, esse contingente da população nacional vivencia sua identidade teuto-brasileira e se ela tem alguma importância nas parcerias bi-nacionais que Brasil e Alemanha vêm desenvolvendo nos campos econômico, social e cultural.

A pesquisa, apesar de ser apenas um estudo do contingente alemão na cidade de Campinas, buscou iniciar uma reflexão mais ampla que procura avaliar como o grupo imigrante teuto, um dos primeiros a ser chamado para substituir o braço escravo nas grandes plantações cafeeiras paulistas do século passado, aqui se fixou, se reproduziu e prosperou trazendo certa- mente contribuições para a formação da sociedade paulista, e como hoje a base sócio-política e cultural criada a partir da imigração germânica de meados do século passado e enriquecida por levas posteriores quantitativamente menores, permite uma intensa relação econômica e cultural entre essa região do país e a Alemanha, uma nação que neste final de século se afirma novamente como uma das maiores forças econômicas e políticas do Mundo Ocidental.

Foram reunidas as histórias de vida dos membros mais velhos das colônias imigrantes vivendo nas zonas rural e urbana

Foto: Acervo do Projeto Família, Imigração e Cultura do Centro de Memória/UNICAMP, Coordenado pela Prof ${ }^{\text {. Dr }}$. Olga von Simson.

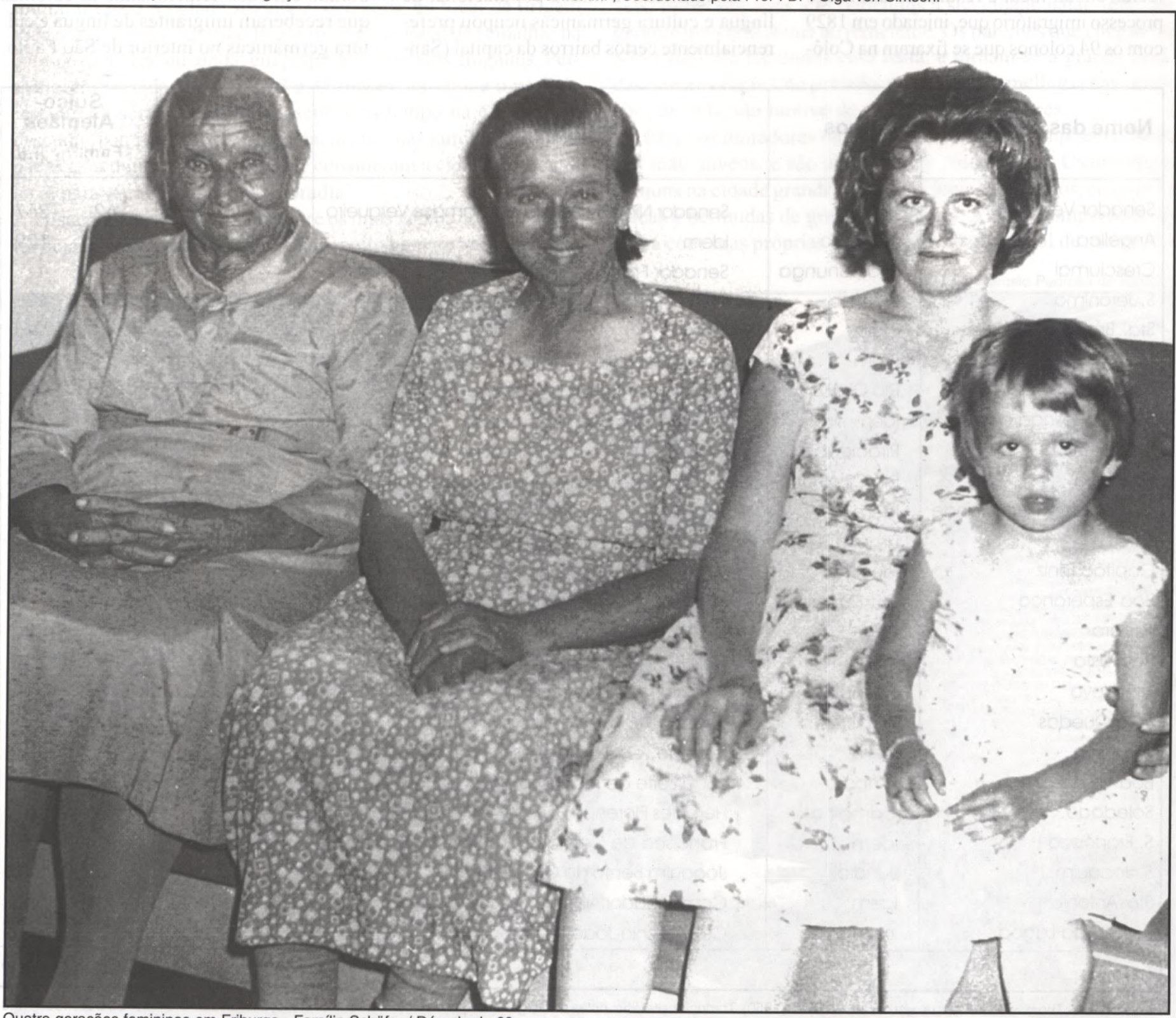

Quatro gerações femininas em Friburgo - Família Schäfer / Década de 60. 
procurando focalizar o processo de escolarização e as atividades familiares relacionadas ao lazer e ao consumo cultural. Também foram coletados documentos oficiais e privados relacionados ao processo imigratório dessas famílias, fotografias antigas e publicações com o intuito de orientar a coleta das narrativas orais e complementá-las.

A hipótese original que orientou a investigação foi a de que os imigrantes alemães, quando comparados com outros grupos, já haviam chegado ao Brasil com padrões educacionais e culturais mais elevados. Este fato teria feito com que as familias do contingente estudado tivessem maior cuidado com a educação de seus filhos, suprindo mesmo com esforço próprio, as deficiências do meio social brasileiro. A vida em família incluiria também atividades de caráter cultural, como leitura e música e, pelo menos parte do lazer dessas famílias, seja em casa ou em comunidade, seria dedicada às atividades culturais. Com tais atitudes as famílias estariam instrumentalizando muito melhor os seus filhos para enfrentar a vida na nova sociedade e permitindo aos mesmos realizar uma ascensão mais rápida na estrutura da sociedade urbana brasileira, confirmando o senso comum vigente na sociedade mais ampla que afirma que este foi um dos grupos imigrantes que "deu mais certo".

A análise dos dados colhidos em arquivos nacionais e internacionais ou junto aos descendentes mais idosos pelo método biográfico, assim como o trabalho com um rico acervo de fotografias antigas em poder da comunidade, nos fez perceber que além do papel fundamental das famílias de cultura camponesa no processo de educação de seus muitos filhos também o movimento associativo, engendrado na pequena colônia de origem germânica, isolada no "sertão de Campinas", foi decisivo para definir o tipo e a qualidade da inserção desses teuto-brasileiros na sociedade brasileira mais ampla da região de Campinas.

Foi a capacidade de criar e manter associações, trazida por esses imigrantes das suas experiências anteriores na Mãe-Pátria, que permitiu a eles superar as carências e dificuldades vivenciadas no período de instalação no bairro rural por eles criado. Ante a total indiferença manifestada nessa fase inicial, tanto pelo governo alemão (por quem eram taxados como "traidores da Pátria", ao abandoná-la para vir tentar nova vida na América), quanto pelo brasileiro (que se interessava por imigrantes teutos, ou como mão-de-obra substituta para a escrava nas fazendas cafeeiras ou como contingente populacional utilizado para desenvolver áreas devolutas e de difícil ocupação pela agricultura de exportação) os imigrantes de Friburgo tiveram que buscar em vivências e conhecimentos trazidos da Terra-Mãe Alemanha ou adquiridos no longo período (10 a 20 anos) em que funcionaram como "parceiros" nas fazendas de café da região, as estratégias para sobreviver e prosperar no "sertão sul do município",

Foi assim que a partir do último quartel do século passado e até a década de 30 deste século eles viveram como prósperos pequenos sitiantes que plantavam café (então o produto agrícola de mais alta rentabilidade) e puderam erguer e manter comunitariamente a escola, o cemitério e a igreja luterana locais, além de uma biblioteca utilizada por toda comunidade, grupos de canto coral e espaços de lazer cultural, como as peças de teatro encenadas anualmente na escola, e as festas em datas marcantes para a vida local.

Mas o crescimento natural dessa comunidade teuto-brasileira, as transformações econômicas e sociais da região e a crise do café de 29/30 determinaram o início de um processo gradativo e cada vez mais acelerado de inserção dos descendentes dos pioneiros de Friburgo na sociedade urbana da região nas cidades de Indaiatuba, Campinas e Monte Mor (Von Simson, 1997).

A pesquisa, na sua segunda fase acompanhou as trajetórias de três famílias de Friburgo e comparando-as com trajetórias de três outras famílias também de origem germânica mas fixadas em contexto urbano, procurou entender como se deu esse processo de inserção e assimilação dos teuto-brasileiros na sociedade de Campinas e região.

Partindo do pressuposto de que o grau mais elevado de inserção e aceitação do imigrante ou descendente de imigrante na sociedade mais ampla local pode ser percebido quando ele assume uma participa- ção política na vida do município (ou do estado, ou da federação), tentamos examinar comparativamente trajetórias de famílias onde esse fato pode ser observado e outras onde tal tipo de inserção não se realizou.

Assim, as famílias estudadas nessa segunda fase da pesquisa foram selecionadas dentro do nosso universo anterior levando em conta essa preocupação da pesquisa.

A comparação entre as famílias fixadas seja em zona rural ou em zona urbana e realizada por gerações levou em conta as seguintes categorias: educação (realizada na comunidade ou também em escolas urbanas), profissões exercidas ao longo da vida, casamento (endogâmico ou exogâmico) religião e identidade manifestada pelo entrevistado.

Finalmente tentamos examinar como foi construída e se é mantida entre eles uma identidade teuto-brasileira e quais as transformações que esta auto-identificação sofreu ao longo das duas grandes guerras e na contemporaneidade.

Neste artigo comparamos as trajetórias de três gerações das famílias fixadas, a princípio em Friburgo na zona rural, e posteriormente em habitat urbano para tentar perceber como cada uma delas enfrentou o desafio da integração à sociedade mais ampla brasileira e a construção de uma identidade no bojo da modernidade.

A primeira geração de entrevistados (hoje com 60 a 88 anos) sofreu influência da ideologia da Liga Pan-Germânica (Alldeutscher Verband) atuante desde os nos 90 do século passado. Essa organização nacionalista radical com seu caráter expansionista esforçava-se por introjetar um forte sentimento nacionalista nos "alemães do exterior" (conceito por ela mesma inventado) como estratégia indireta de assegurar acordos econômicos naquelas nações (Magalhães, 1993, p.56; Seyferth, 1994), que haviam recebido imigrantes teutos. A liga financiou empresas de seus compatriotas mais abastados e colaborou também para a manutenção de escolas, associações, igrejas, bem como ampliou a imprensa de língua alemã. Apoiava a endogamia, veiculando doutrinas de cunho racial (Magalhães, 1993, p.57).

Os instrumentos transmissores dessa influência eram os professores que vindos 
da Alemanha ou de colônias do sul do país traziam uma visão tradicional e nacionalista do papel do colono-imigrante e da importância da manutenção da língua alemã como instrumento de comunicação entre os colonos, além de enfatizarem, na sua atuação concreta, os hábitos e costumes de origem teuta.

Também a religião luterana, através de seus pastores teve um papel relevante nesse processo como denotam as palavras do pastor Wilhelm Rotermund que influenciou os alemães fixados em nosso país através do jornal "Deutsche Post" e dos almanaques "Kalender für die Deutschen in Brasilien", por ele editados e difundidos pela Igreja Luterana em todo o Brasil. Dizia ele "O cultivo da germanidade está no sangue da Igreja Evangélica que, com razão, foi designada de fruto da união do Evangelho com o espírito germânico quem deixa de pensar evangelicamente, deixa de ser alemão e vice-versa. Quem nega a língua e a índole alemã também se perderá muito possivelmente para nossa igreja" (Magalhães, 1993, p.66).

O hábito da compra dos almanaques ou Kalenders se mantém entre as famílias residentes na zona rural como pudemos constatar em entrevista realizada em 1994 com uma família de Friburgo e essa obtenção é intermediada, ainda hoje, pela Igreja Luterana. A reserva precisa ser feita nos meses finais do ano, pois a edição parece ser limitada, não havendo número suficiente de "Kalenders" para todos os interessados.

Um indicador concreto dessa influência pode ainda hoje ser percebido pela carta que o último presidente da Alemanha antes de Hitler, enviou à comunidade de Friburgo, via Consulado Geral de São Paulo e que se encontra num pequeno quadro pendurado na sacristia na igreja local. Nessa carta o presidente alemão diz reforçando o sentimento de nacionalismo:

\section{Der Reichspräsident}

\section{Berlim, 3 de fevereiro de 1933}

Amor pela nova Pátria - fidelidade à velha Terra Natal - este é o sentido no qual os brasileiros de origem alemã sempre se reencontram

\section{von Hindenburg}

Essa influência vai ser reafirmada pela atuação de representantes do nacional-socialismo que na década de 30 frequentaram a comunidade como a escritora e conferencista Maria Kahle, a qual, em sua viagem (financiada pela Liga Popular para a Manutenção do Deutschtum no Estrangeiro) visitou todas as colônias teutas do Brasil, tendo também passado por Friburgo, que assim foi por ela descrito: "Os Holsacianos de Friedburg e os seus descendentes de Monte-Mór se tornaram abastados plantadores de batatas... A escola de Friedburg foi o nosso espaço de reunião, lá e também em Monte-Mór vieram adultos e crianças em grande número, muitos com os cabelos claros de sangue holsaciano. As avós narravam em plattdeutsch os duros tempos iniciais e as associações de canto cantavam músicas populares alemãs" (Kahle, 1937).

Também um serviço de filmes educativos foi montado nessa década, através de um financiamento do sistema ferroviário Alemão que se unindo à Zeiss e à Mercedes e contando com o apoio da Agfa, exibia filmes culturais mostrando os progressos da Alemanha, sob o nacional-socialismo e pretendia filmar a resistência, o dinamismo e a coragem dos colonos teutos que, enfrentando todo tipo de dificuldades, levavam o bom exemplo de trabalho e disciplina e os ideais germânicos aos pontos mais afastados do globo terrestre (von Simson, 1998).

Pretendiam assim fomentar a re-ligação dos filhos da Grande Mãe Alemanha, espalhados pelos cinco continentes com a Pátria de origem.

Todos esses fatores e mais uma educação ministrada em alemão e seguindo um currículo inspirado na escola primária germânica por professores "importados" ou nacionais, mas que haviam cursado a Deutsche Schule de Campinas resultou na construção de uma identidade de tipo tradicional de influência iluminista "com sujeitos auto-centrados, do tipo que se forma em sua relação com os outros" (Mira, 1994, p. 133) e que valoriza a tradição e o nacionalismo e se consubstancia na expressão teuto- brasileiro (Deutsch brasilianer) querendo frisar a diferença em relação à sociedade brasileira mais ampla e se defender da assimilação e sua consequente miscigenação.

A segunda geração das famílias fixadas em habitat rural já apresenta diferença significativa entre os três representantes entrevistados, hoje com 50 a 64 anos de idade. Aquele que permaneceu vivendo na propriedade rural (apenas ausente por um período curto de trabalho em indústrias multinacionais de origem alemã de Campinas) apresenta uma identidade semelhante à da geração anterior na qual a valorização da germanidade se encontra sempre presente e a reafirmação da capacidade de trabalho do teuto-brasileiro é uma constante.

Eu entrei numa firma, a firma chamava ICM: Indústria e Comércio de Máquinas, era máquina pra madeira. Mas o chefe era alemão, quem me levou lá era filho de alemão, era alemão, mesmo, veio da Alemanha, só que ele veio pequeninho - tenho amizade com a familia até hoje; o chefe era alemão, o engenheiro era alemão, o encarregado era alemão, o vendedor era alemão. Então a gente fica dentro daquele ritmo, que o alemão é dificil ele escorregar... Eu acho que... não vamos dizer assim certinho, certinho, mas o sistema que a gente tem já é mais certinho..." (Entrevista com morador da zona rural realizada pela equipe do projeto em 25/1/96, p. 36).

Seus primos, gêmeos que tendo feito o curso primário em Friburgo, migraram para Campinas para continuar estudando em escolas brasileiras nas décadas de 50 e 60 tendo chegado à universidade nos anos 70 , e hoje se encontram vivendo em habitat urbano e integrados ao serviço público e apresentam um outro dipo de identidade de caráter múltiplo na qual a "construção do 'self', ao contrário das culturas baseadas na tradição, tornou-se um processo de negociação constante com o mundo exterior e de reformulação ou reciclagem do eu que, a rigor, nunca termina." (Mira, 1994, p.133) Parece que as transformações trazidas pela modernidade, como diz Anthony Giddens, "na sua extensão... serviram para estabelecer formas de interconexão social que espalmam o globo; em sua intensidade elas vieram alterar algumas das feições mais íntimas e pessoais da nossa existência cotidiana”. (1991, p.133) 
É interessante observar que esses dois irmãos, apesar de gêmeos e de haverem construído uma trajetória escolar idêntica, diferenciam-se na maneira como construíram a identidade múltipla de caráter conjuntural. Ambos concordam com os anos 50 e 60 quando cursavam a escola secundária em Campinas., recém-chegados de Friburgo e com dificuldades para dominar plenamente o idioma português, foram anos muito dificeis que os levaram a "negar" a sua origem germânica e a procurar uma integração rápida à vida urbana brasileira.

O "mais velho", sempre muito ligadoà Igreja Luterana e aos movimentos de juventude por ela promovidos, manteve-se mais germânico tendo buscado nos locais onde viveu estabelecer relações com contemporâneos de mesma fé e origem cultural e tendo talvez por isso se casado com uma jovem de origem suiço-alemã.

nós entramos na Universidade em Curitiba. Ai nós cursamos os quatro anos... $O$ $R$. sempre mantendo mais ligação com a colônia que eu... Não a colonia em si, mas a nível da Igreja. Ele sempre foi muito amigo do pastor, então ele tava sempre em contato com juventude, essas coisas. Ele foi viajar muitas vezes para o Rio Grande do Sul, mas... eu parti pro outro lado que era o futebol pra brincar. era completamente diferente do que ele participava... "' (Entrevista com Júlio Gübel, realizada pela equipe do projeto em 13/1/96, p.7).

É ele que, na idade madura, vai liderar um movimento de reconstrução da tradição germânica na Associação do bairro rural de Friburgo que presidiu por duas vezes e tomar a iniciativa de buscar na Universidade o apoio necessário para realizar uma re-ligação (com bases científicas) do grupo de descendentes de alemães com a pátria de origem, através de uma pesquisa na qual o grupo pesquisado atuou efetivamente, colaborando com depoimentos, imagens fotográficas e documentos pessoais.

O irmão "mais jovem" construiu, ao longo de sua vida escolar nas várias instituições que cursou, seus grupos de relacionamento, através do esporte e conviveu, portanto, com amigos de diferentes origens étnicas e culturais, elaborando uma identidade muito mais próxima da brasileira o que o levou talvez a se casar com uma descendente de italianos.

.. meu irmão sempre jogava futebol de salão, uma ou duas vezes por semana ele ia pra cidade (Jaboticabal), eles vinham buscar ele prajogar futebol, então ele se integrou dessa maneira... "Entrevista com Ricardo Gübel Jr., realizada pela equipe do projeto em 5/1/96, p.13).

Hoje, ambos participam ativamente da Sociedade Escolar do Bairro de Friburgo trazendo seus filhos adolescentes e universitários para vivenciar as tradições alemãs recriadas, via grupo de dança folclóricas, mas a inserção do "mais jovem" nesse processo foi mais lenta e gradativa como se a reconstrução do componente germânico da sua identidade precisasse de mais tempo e motivações várias para se processar.

A terceira e última geração entrevistada é formada pelos jovens que tendo nascido e se criado nas cidades de Campinas e Indaiatuba e cursado as escolas brasileiras, pouca importância davam para Friburgo, vista muitas vezes como local de moradia dos parentes mais idosos e sem muitos atrativos que os fizessem optar por lá passar seus fins de semana. A ascendência germânica pouco significava para esses jovens que organizavam seu tempo livre entre as atividades dos clubes e os cinemas nos shopping centers das cidades interioranas, negando-se a participar das comemorações com apelo étnico que seus pais ou tios passaram a realizar no bairro rural desde meados da década de 80 .

Foi a partir de 1993, através da criação em Friburgo de um grupo de danças folclóricas liderado por um casal de origem teuto-brasileira de São Paulo transferido para Indaiatuba, que esses jovens passaram a frequentar a Associação Escolar, uma espécie de clube nos fins de semana, para a comunidade friburguense. Aprendendo a dançar as elaboradas evoluções que recriam os costumes do Norte da Alemanha, região de onde vieram seus trisavós, essa juventude foi desenvolvendo uma identidade teuto-brasileira e se interessando por aprender o idioma de seus antepassados.

Quando perguntados sobre as razões que os levaram a integrar o grupo de danças, dois motivos aparecem como predominantes: o prazer da dança e a oportunidade de conhecer um pouco da cultura alemã, tendo já alguns destes jovens começado a estudar o idioma de Goethe.

Não se percebe entre eles, entretanto, um culto à tradição, nem uma nostalgia de um tempo passado em que a germanidade imperava, mas sim um sentido muito pragmático que coloca um certo domínio da cultura e língua teutas como fatores positivos para a vida profissional futura.
Trata-se de uma volta ao passado, com as percepções do presente, mas visando um futuro relativamente próximo onde a forte competição no mercado de trabalho poderá ser enfrentada com trunfos extras, fornecidos pela identidade teuto-brasileira recém adquirida e usada estrategicamente.

É assim que expressando sua germanidade através da dança dos ferreiros, originária das corporações de ofício medievais do norte europeu eles desenvolvem coordenação motora e flexibilidade que lhes permitem executar espontaneamente, alguns minutos depois, após o término da apresentação oficial, a "dança da garrafa" de origem baiana contemporânea, com muita habilidade e alegria, intercalando assim como diferentes faces de um caleidoscópio, as muitas características de suas identidades múltiplas.

* Olga Rodrigues de Moraes von Simson - F.E./ UNICAMP-Centro de Memória / NAP - CERU - USP - CNPq.

\section{NOTA}

1. Nossa pesquisa, bem como o corpo deste texto, tem como base levantamento efetuado junto ao Arquivo para Relações com Países Estrangeiros de Stuttgart/Alemanha.

\section{BIBLIOGRAFIA}

GIDDENS, Anthony

(1991) As consequências da modernidade. São Paulo, UNESP.

KAHLE, Maria

(1937) Deutsch Heimat in Brasilien Berlin. Verlag Grenze und Ausland.

MAGALHÃES, Marionilde Dias B.

(1993) "Os imigrantes alemães e a questão da cidadania". In: Textos de História, v.I, № 2 .

MIRA, Maria Celeste

(1994) "O global e o local: mídia, identidades e usos da cultura". In: Revista Margem, n³, São Paulo, EDUC.

SEYFERTH, Giralda

(1994) "Identidade étnica, assimilação e cidadania: A imigração alemã e o Estado brasileiro". In: Revista Brasileira de Ciências Sociais. ANPOCS, $n^{\circ} 26$, ano 9, pp. 103-122.

VON SIMSON, Olga

(1997) "Diversidade sócio-cultural, reconstituição da tradição e globalização: os teuto-brasileiros de Friburgo/Campinas". In: Familia em São Paulo: Vivência na diferença. São Paulo, CERU/Humanitas, (Coleção Textos, Série 2, n7), pp.63-75.

VON SIMSON, Olga

(1998) "Imagem e Memória". In: O Fotográfico. (Org. Etienne Samain), São Paulo, Hucitec/CNPq. 